\title{
LONGEVITY IMPROVEMENT OF OPTICALLY ACTIVATED, HIGH GAIN GaAs PHOTOCONDUCTIVE SEMICONDUCTOR SWITCHES
}

\author{
A. Mar, G. M. Loubriel, F. J. Zutavern, M. W. O'Malley, W. D. Helgeson, \\ D. J. Brown, H. P. Hjalmarson, and A. G. Baca \\ Sandia National Laboratories, Albuquerque, New Mexico 87185-1153
}

\section{ABSTRACT}

The longevity of high gain GaAs photoconductive semiconductor switches (PCSS) has been extended to over 100 million pulses at $23 \mathrm{~A}$, and over 100 pulses at $1 \mathrm{kA}$. This is achieved by improving the ohmic contacts by doping the semi-insulating GaAs underneath the metal, and by achieving a more uniform distribution of contact wear across the entire switch by distributing the trigger light to form multiple filaments. This paper will compare various approaches to doping the contacts, including ion implantation, thermal diffusion, and epitaxial growth. The device characterization also includes examination of the filament behavior using open-shutter, infra-red imaging during high gain switching. These techniques provide information on the filament carrier densities as well as the influence that the different contact structures and trigger light distributions have on the distribution of the current in the devices. This information is guiding the continuing refinement of contact structures and geometries for further improvements in switch longevity.

The filamentary nature of the current in high-gain PCSS impacts negatively the operational lifetime of the switches. This is manifested in the form of damage of the semiconductor to metal interface that initially appears as a trench, metal erosion, or damage in the GaAs away from the contacts (in the gap between the contacts). Contact erosion is an important damage mechanism since it is the main cause of degradation of switching characteristics, resulting in higher on-state resistance and voltage drop, and ultimately the ceasing of switch function. We have previously shown that the trigger light can be applied to diffuse the filaments near the contacts, improving the current distribution and longevity. A refinement of this technique is the use of multiple filaments using multiple line triggering as shown in Figure 1 . In this example we have used trigger light imaged into 8 lines across the width of the switch to initiate 8 distinct filaments that the current will be distributed amongst. When triggered in this manner, switching at nominally $1000 \mathrm{~A}$ results in current drop of only $13 \%$ after 100 shots, with continuing switch functionality. The same switch operating at only $90 \mathrm{~A}$ shows a $28 \%$ current drop when fiber (spot) triggered after 86 shots, at which point complete switch failure occurs.

Due to the improvements in current distribution and lifetime demonstrated by the optical generation of carriers near the contacts, we have sought to incorporate doped layers with high carrier concentrations under the contact regions to reduce the contact resistance and spread the current when single point (fiber) triggering is used. Such structures are shown in Figure 2. The doped regions also serve to transfer the point of filament termination from the metal - semiconductor interface to a doped semiconductor - semiconductor interface that is more robust against damage. Two main approaches for the fabrication of switches with doped contact layers are being developed. The first is patterned epitaxial regrowth. In this process, the contact regions are etched to some depth (a few microns) and highly doped GaAs is then regrown into these regions by the same thickness as the etch depth using a growth mask $\left(\mathrm{SiO}_{\mathrm{x}}\right)$ that prevents growth elsewhere. Ohmic contacts made to the doped layers, which results in a planar structure. Because of non-idealities associated with the patterned regrowth, this process is still in development to overcome the issues of conductive material grown on the growth mask (into the switch gaps), and growth non-planarity. The second technique we are pursuing for doped PCSS contacts is dopant diffusion. In this process, $\mathrm{SiN}_{\mathrm{x}}$ is deposited and patterned to serve as a diffusion mask for $\mathrm{Si}$ and $\mathrm{Zn}$ dopants. Ohmic contacts are then made to the doped regions to complete the fabrication. A microphotograph of such a completed device is shown in Figure 3.

IR imagery of PCSS filaments shows that the doped layers are highly effective in the suppression of the filament formation near the contacts as shown in Figure 4. This filament suppression at the contact is effective for peak current levels of up to approximately 40-60A. In this regime, damage-free operation of the switch is obtained and the device is expected to be extremely long-lived. At 23A, we obtained 100 million shots at which point the test was stopped, although the switch was still operating.

The level of current that can be switched without damage is dependent on the thickness of the doped layer beneath the contact. This was determined by preparing samples over a range of p-type anode diffusion depths (from $\sim 1 \mu \mathrm{m}$ to $\sim 4 \mu \mathrm{m}$ ). The maximum current for damage-free operation was then determined for the different diffusion depths. This was done accounting for two types of damage: damage confined to the contact metal (no switching current degradation), and damage to both the contact metal and bulk GaAs (switching current drops as damage accumulates). This characteristic is plotted in Figure 5. Increased dopant diffusion depths clearly aid in suppressing damage to the bulk semiconductor. However, the improvement for damage to the contact metal tends to a limit of approximately $40 \mathrm{~A}$, with no furher improvements with increasing diffusion depth. This implies a different mechanism for damage to the metal that is not adequately addressed by the current spreading in the doped contact layer. This indicates the requirement for a separately engineered solution for the fabrication of the contact metals, together with the doping in the semiconductor material. or the implementation of field shaping and/or multiple filaments to enhance the lateral spreading of current at the contacts.

Sandia is a multiprogram laboratory operated by Sandia Corporation, a Lockheed Martin Company, for the United States Department of Energy under Contract DE-AC04-94AL85000. 


\section{DISCLAIMER}

This report was prepared as an account of work sponsored by an agency of the United States Government. Neither the United States Government nor any agency thereof, nor any of their employees, make any warranty, express or implied, or assumes any legal liability or responsibility for the accuracy, completeness, or usefulness of any information, apparatus, product, or process disclosed, or represents that its use would not infringe privately owned rights. Reference herein to any specific commercial product, process, or service by trade name, trademark, manufacturer, or otherwise does not necessarily constitute or imply its endorsement, recommendation, or favoring by the United States Government or any agency thereof. The views and opinions of authors expressed herein do not necessarily state or reflect those of the United States Government or any agency thereof. 


\section{DISCLAIMER}

Portions of this document may be illegible in electronic image products. Images are produced from the best available original document. 


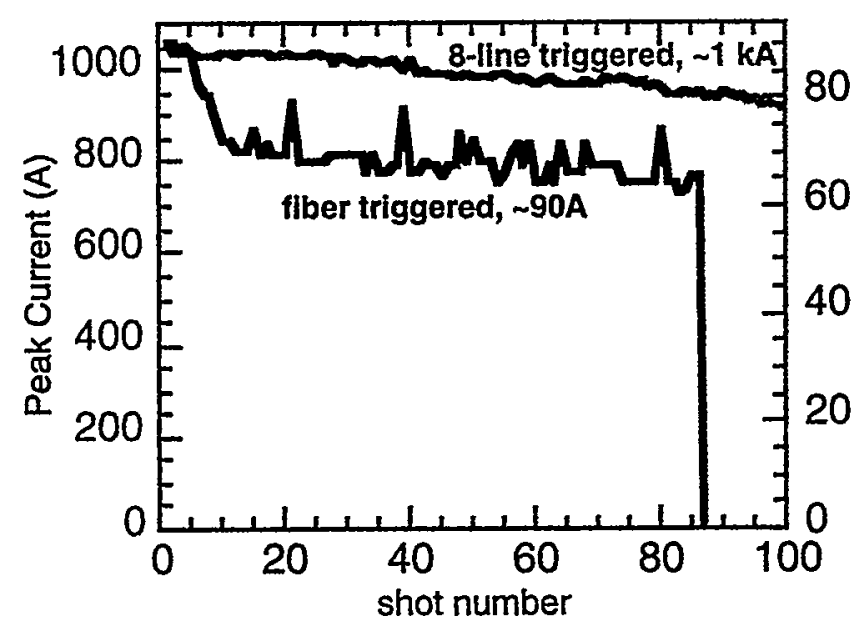

Figure 1. Switch lifetime improvement using multiline vs. fiber spot triggering.

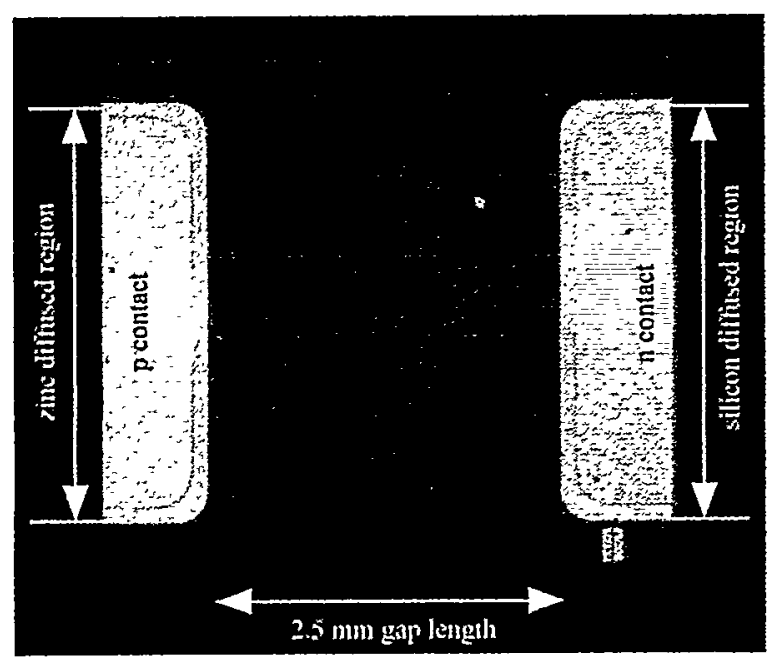

Figure 3. Microphotograph of completed PCSS with diffusion-doped contacts.

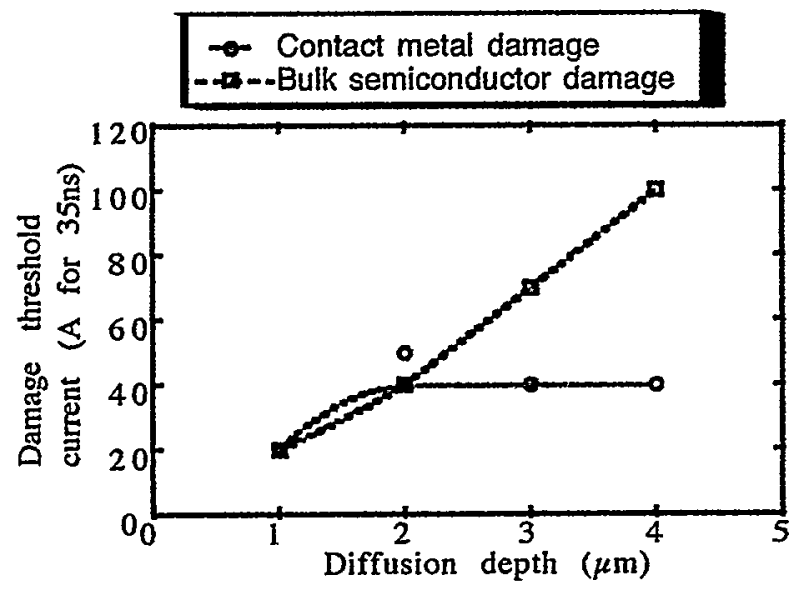

Figure 5. Dependence of contact damage thresholds on diffusion depth.
Conventional switch:

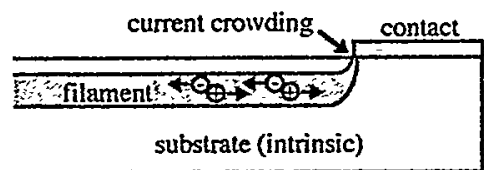

Switch with doped contact layer.

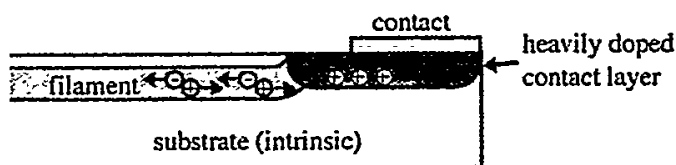

Swilch w/doped contact and resistive current-leveling layers:

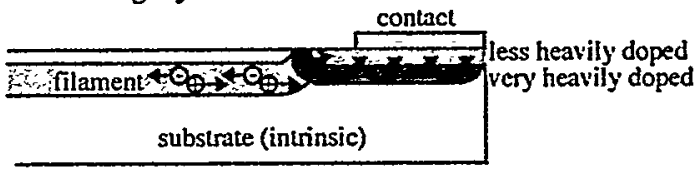

Figure 2. Doped contact structures for alleviation of current crowding in PCSS.

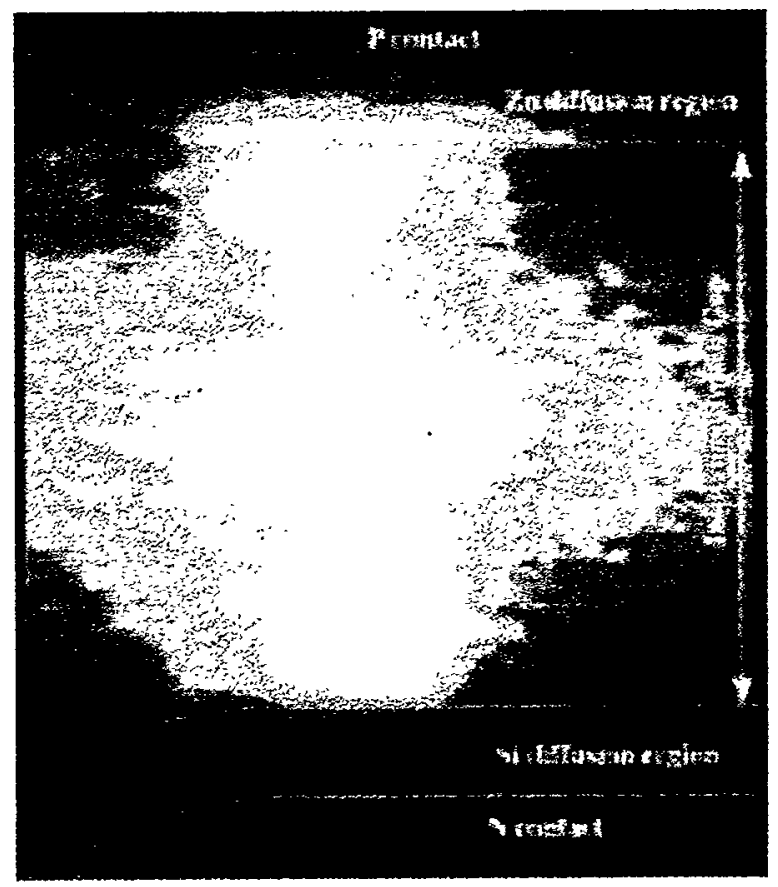

Figure 4. Filament suppression in the doped contact regions of a PCSS. 